www.jmscr.igmpublication.org Impact Factor 5.244

Index Copernicus Value: 83.27 ISSN (e)-2347-176x ISSN (p) 2455-0450 crossref DOI: _https://dx.doi.org/10.18535/jmscr/v4i12.32

\title{
Resident Doctors Education on Appropriate Utility of Blood Components
}

\author{
Authors \\ Abdul Wahid Bhatt MBBS, MD, MRCP ${ }^{1}$, Dr Ajaz Nabi Koul MBBS, MD, MRCP \\ ${ }^{1}$ Associate Professor Emergency Medicine, Sher-I-Kashmir Institute of Medical Sciences, Soura, Srinagar \\ Kashmir, India \\ ${ }^{2}$ Associate Professor Internal Medicine, SKIMS Soura Srinagar Kashmir India \\ Corresponding Author
}

Abdul Wahid Bhat. MBBS, MD, MRCP

Associate Professor Emergency medicine

Sheer-I-Kashmir Institute of Medical Sciences, Soura, Srinagar Kashmir, India

Email: bhatabdulwahid@yahoo.com Cell:-9419526285

\begin{abstract}
At Sher-I-Kashmir institute of medical sciences, Soura Srinagar Kashmirs we, analyzed 1109 transfusion episodes for different blood components for their rationale use. 713(64.2\%) were appropriate and $386(35.7 \%)$ were inappropriate. This was followed by extensive regular training and education of treating resident staff about rationale use of blood components. There were 833 episodes of transfusion 760 $(90.1 \%)$ were found appropriate and 73 (9.9\%) were inappropriate $<0.5$.The distribution of inappropriate use was homogenous for all components and was in the range of 32\%-40\%-and dropped by $25 \%$ fallowing education of treating resident staff.

Keywords: Blood components, Inappropriate, Appropriate, Rationale.
\end{abstract}

\section{Introduction}

Blood and its components are an important part of patient management protocols and like drugs have property to cause adverse reactions in the recipients. However, it is in its judicious use that lays its real benefit. The blood component implies separation of whole blood into various potential components like packed red cells, platelet rich plasma, fresh frozen plasma, cryoprecipitate and leucocytes. All patients requiring transfusion should have a reliable access to safe blood products, including whole blood, labile blood components and plasma-derived medicinal products, appropriate to their clinical needs, provided in time and administered safely. Data on the use of blood products are limited, but studies suggest that blood products are often overprescribed in both developed and developing countries. ${ }^{1}$ To maximize the effectiveness, safety and utility clinicians and intravenous therapists should be knowledgeable about the potential risk of blood component therapy. Therefore, the clinician should keep in mind the appropriate indication for ordering blood components there by avoid misuse and unnecessary exposure of the recipient to various infectious and non-infectious complications. 
Hence, regular audit of blood and its component usage are essential to access the blood utilization pattern and set ideal policies in all the blood using specialties. In spite of the sophisticated blood banking services worldwide; indiscriminate use of blood components with either no indication or inappropriate indication continues. Various strategies have been developed to reduce the inappropriate use of blood components. These include guidelines and consensus conferences as well as monitoring of transfusion practice, education, and self-audit byclinicians. ${ }^{2,34}$ The clinical practice guidelines for the use of blood components aim to improve the consistency and appropriateness of transfusion practice; promote the integration of quality management systems into transfusion practice; reduce the overall number of transfusion-related complications; increase consumer awareness of the benefits and risks of blood component therapy; and conserve a limited resource. ${ }^{3}$

\section{Material and Methods}

This study was done in Emergency Medicine Department at Sher-I-Kashmir institute of medical sciences Soura Srinagar Kashmir over one year period from July 2015 to June 2016. Data was collected using a prospective analysis of blood and its component requisitions from department of emergency medicine regarding diagnosis, indication for transfusion, number and type of blood and component units requested. Reports of silent investigations like hemoglobin, platelet count, coaglogram were also recorded. Rational use of blood was assessed by determining prevalence of appropriateness using World Health Organization (WHO) clinical practical guidelines and transfusion indices. Interviews were done with doctors to assess their knowledge and practice of blood and component usage. Nature of component and their quantity used was correlated with disease indication for transfusion of a particular component.

\section{Results}

The present study was conducted upon 1109transfusion episodes for different blood components over a period of one year from July 2009 to June2016.Of the total of 1109 transfusion episodes in 622 patients. Prior to education of resident staff about blood and component use 246 requests were for packed red cells, 164 for fresh frozen plasma, 186 for plasma, 350 for platelet rich plasma and 163 episodes for cryoprecipitate. Of the total 1109 episodes; $713(64.29 \% \%)$ episodes were appropriate and 396 (35.7\%) transfusions were inappropriate. table: 1 . The treating residents were educated about the guide lines ,indications, preparation ,preservation and appropriate utility of blood components regularly in emergency medicine in the form of lectures and bed side discussions and requests for various blood and blood components were issued after consultation or supervision of a senior doctor in the department and such requests were again checked for their appropriateness. Table: 3 The disease parameters for which components were utilized are shown in table: 2

Table 1. Distribution of blood component use prior to resident education

\begin{tabular}{|l|c|c|c|}
\hline Component & Appropriate & Inappropriate & Total \\
\hline Red blood cells & $167(67.9 \%)$ & $79(32.1 \%)$ & 246 \\
\hline Fresh frozen plasma & $109(66.46 \%)$ & $55(33.53 \%)$ & 164 \\
\hline Plasma & $117(62.95 \%)$ & $69(37 \%)$ & 186 \\
\hline Platelet rich plasma & $209(59.7 \%)$ & $141(40.2 \%)$ & 350 \\
\hline Cryoprecipitate & $111(68.0 \%)$ & $52(32 \%)$ & 163 \\
\hline Total & $713(64.29 \%)$ & $396(35.7 \%)(\mathrm{p}<0.5)$ & 1109 \\
\hline
\end{tabular}


Table: 2 Distribution of blood component use fallowing resident education

\begin{tabular}{|l|c|c|c|}
\hline Component & Appropriate & Inappropriate & Total \\
\hline Packed red cells & $178(90.8 \%)$ & $18(9.2 \%)$ & 196 \\
\hline Fresh frozen plasma & $141(85.97 \%)$ & $23(14 \%)$ & 164 \\
\hline Plasma & $88(91.66 \%)$ & $8(8.3 \%)$ & 96 \\
\hline Platelet rich plasma & $228(93.0 \%)$ & $17(7 \%)$ & 245 \\
\hline Cryoprecipitate & $119(87.1 \%)$ & $13(12.8 \%)$ & 132 \\
\hline Total & $760(90.1 \%)$ & $73(9.9 \%) \mathrm{p}<0.5)$ & 833 \\
\hline
\end{tabular}

Table: 3 Distribution of components as per the disease

\begin{tabular}{|l|c|c|c|c|c|}
\hline Diagnosis & PRC'S & FFP & PRP & Plasma & Cryo \\
\hline Anemia & 116 & - & - & - & - \\
\hline Deranged PT & 06 & 32 & 12 & 13 & - \\
\hline Hemophilia & - & 62 & - & 2 & 144 \\
\hline Thrombocytopenia & - & - & 121 & - & - \\
\hline Bleeding & 13 & 22 & 44 & - & - \\
\hline Chronic liver disease & - & 20 & 35 & 80 & - \\
\hline Hypotension & 5 & 9 & - & 12 & - \\
\hline CKD with bleeding & 32 & 8 & 23 & - & - \\
\hline Gynecological problems & 23 & 11 & 30 & 79 & - \\
\hline Leukemia's & 51 & - & 85 & - & - \\
\hline Total & 246 & 164 & 350 & 186 & 163 \\
\hline
\end{tabular}

\section{Discussion}

Rational use of blood implies that blood is to be given to the patient only when needed. Regular audit of blood and its component usage are essential to access the blood utilization pattern and set ideal policies in all the blood using specialties. In spite of the sophisticated blood banking services worldwide; indiscriminate use of blood components with either no indication or inappropriate indication continues. Various strategies have been developed to reduce the inappropriate use of blood components. These include guidelines and consensus conferences as well as monitoring of transfusion practice, education, and self-audit by clinicians. ${ }^{(2,3,4,)}$ The clinical practice guidelines for the use of blood components aim to improve the consistency and appropriateness of transfusion practice; promote the integration of quality management systems into transfusion practice; reduce the overall number of transfusion-related complications; increase consumer awareness of the benefits and risks of blood component therapy; and conserve a limited resource. ${ }^{5}$ Internal audits form an integral part of the quality control program in any blood bank, like in any other organization. Blood and blood products are considered drugs by the food and drug administration (FDA). ${ }^{6}$ Indiscriminate use of blood components is on a rise due to easy availability of sophisticated blood banking services. 7Itis important for the blood bank to be able to fulfil the demands for this life saving product and at the same time, evaluate and access the existing trends of blood ordering. First audit of transfusion practices was done by Bock as early as 1936. As a fact the supply of blood and blood components are finite, a high rate of inappropriate use has been reported around the world. This inappropriate use of blood and its components have a significant impact on the patients and the hospital staff in the form of health care cost, wastage of resources, depriving more needy patients and transmission of infection with unnecessary allergic reaction leading to high morbidity in patients. ${ }^{8}$ The over view of appropriateness of transfusion of various blood components in our study revealed that of the total 1109 transfusion episodes $713(64.29 \%)$ were inappropriate. The number of inappropriate requests for different components was in the range 
of $(32 \%-40 \%)$. There are many reports available regarding inappropriate transfusion of blood components at various centers showing $29 \%$ $40 \%$ blood components being used inappropriately ${ }^{[9,10,11,12]}$. Presently with the advent of blood component usage for specific needs of patients better guide lines have been suggested and put into practice globally. It is now a standard practice of all blood banks to manufacture different blood components from donated whole blood units and supply only components thereafter to patients. ${ }^{[13,14,15,16]}$ However use of whole blood is recommended in certain situations, instead of replenishment of blood loss through components. One such situation where use of whole blood is preferentially indicated is poly trauma. Advanced trauma support (ALTS) guidelines recommend blood transfusion in class III and IV hypovolumia in adults. ${ }^{[16,17]}$ An actively bleeding patient who has already received 4 units of packed red cells needs to be transfused with whole blood as it not only replenishes but prevents dilution of coagulation factors too. A misconception about FFP that, it is a good volume expander and a source of albumin does not hold true. In the present study FFP was given inappropriately for chronic liver disease, chronic kidney disease and hypotension without derangement of coagulation tests. This, in emergency situations may lead to inappropriate high use of PRCs and FFP as has been reported by others. ${ }^{[18,19,20]}$ Mozes et al depicted a much higher rate of inappropriate use of PRCs. ${ }^{18}$ while, Hume et al found $5.95 \%$ of PRCs to be inappropriate ${ }^{[19]}$, It is recommended to transfuse 5-6 units of FFP to correct the hemostatic defect due to clotting factor deficiency, but most often 1-2 units are being transfused. Cryoprecipitate transfusions were found inappropriate in $32 \%$ episodes and were prescribed by residents in emergency situation in patients with hemophilia without active bleeding or prolongation of coagulation profile and few cases of bleeding due to thrombocytopenia. All the resident staff of the department of emergency medicine was regularly educated about the preparation, preservation, indication, contraindication, complications and appropriate utilization of blood components through lectures and bed side discussions. Fallowing this exercise the blood component utility was re-examined for a period of next six months. There were 833 episodes of transfusion for different components and73 (9.9\%) were found inappropriate and760 (90.1\%) were appropriate with drop in inappropriate use by $25.8 \%(\mathrm{p}<0.5)$.Yeh et al ${ }^{[21]}$ carried out audit on FFP use and fallowed it by five sessions of education on transfusion guidelines which resulted in $30 \%$ decrease in inappropriate use of FFP. Hawkins TE. [5] Instituted a system of pre transfusion approval which resulted in $33 \%$ decrease in units of FFP transfusions. It should be in fact an aim of all blood banks to achieve even higher rate of appropriate transfusion of various blood components. The limited available information from developing countries also suggests that blood transfusion practices are not in accordance with international guidelines for safe and rational use of blood transfusions. Doctors do not consistently follow any standard guidelines and base their decision to transfuse on anticipated blood loss, past experience, subjective personal judgment, misconceptions, myths and prescribing by habit. $^{22,23,24}$

\section{Conclusion}

Blood and blood components have a limited resource. Periodic review of blood component usage is very important to access the blood utilization pattern in any hospital. Develop guidelines for rational use of blood along with internal audit which, will help decrease their inappropriate use. Patients should be given blood transfusion only for valid indications. This will ensure availability of components to needy patients and save many patients from transfusion related reactions also. Organizing clinician awareness education and training, establishment of guidelines in wards and regular audit will prove a fruit full exercise to increase the appropriate use blood components. 
Conflict of interest; Nil

Financial assistance: Nil

\section{References}

1. World Health Organization, Blood Transfusion Safety, Safe and rational clinical use of blood,

URL:http://www.emro.who.int/programme areas bloodsafety.htm

2. Rationale use of blood product, European Journalof Cancer, 2001; 37(18) : 24212425.

3. Blood Component Transfusion Guidelines For Transfusing Physician .Handbook of Blood Banking and Transfusion Medicine, Jaypee Brothers Medical Publishers Ltd, new Delhi,2006,P:122-145.

4. World Health Organization, The Clinial Use OfBlood.p;21-32

5. The NHMRC/Australasian Society of Blood Transfusion (ASBT) Clinical Practice Guidelines on the Use of Blood Components (2001)

6. Hillyer CD, Silberstein LE, Ness PM, Anderson KC(Eds) 2003 Blood banking and transfusion Medicine.2nd Edition Churchill Livingstone, New York

7. Rationale use of blood components an audit Minalwade,Ratna Sharma, Mamta Manglani Indian J. Hemotolblood Transfusion 2009; 25 (2):66-69

8. An audit of fresh frozen plasma usage in an acute generalhospital in Singapore. Singapore Med Journal2003; 44 (11):574576

9. Midori K, Keiko N, Kuninori k, Yuriko N, Yoko Y. Blood component use at an emergency critical Unit Fukuokauniversity hospital Japanese J.Transfusion Med.2005;51:430-434

10. Makroo RN, Raina V, Kumar P, Thakur UK, A prospective audit of transfusion requests in A tertiary carehospital for the use of fresh frozen plasma Asian J.Transfusion sciences 2007; 1:59-61
11. Pratibha R, Jayaranees S, Ramesh JC, Lopaz CG,Vasanthi N. An audit of fresh frozen plasma Usage in atertiary referral centre in a developing country, MalaysJ.Pathol 2001; 23: 41-46

12. Chaudhary R, Singh H, Verma A, Ray V, Evaluation of fresh frozen plasma usage at tertiary Care hospital innorth India ANZ.J.Surgery 2005; 75: 573-576

13. Hawkins TE, Carter JM, Hunter PM, Can mandatorypost transfusion approval programme be improved? Transfusion Medicine 1994; 4: 45-50

14. Greene E, McCullough J, Weisdr of D, Platelet utilization and the transfusion trigger: A prospective analysis Transfusion 2007; 47:201-205

15. Zimmerman R, Buscher M, Linhardt C , Handtracle D,Zingsem J,Weisbach V, A survey of blood Componentuse in a German university hospital Transfusion 197;37:1075-1083

16. Harmening DM, Modern blood banking and transfusionpractices. 3rd edition, FA Davis Company Philadelphia

17. World Health Organization .The clinical use of bloodin medicine, obstratics, paediatrics, surgery, anaesthesia, trauma and burns. WHO blood transfusion safety,Geneva?

18. Mozes B, Epstein M, Ben Bassat I, Modan B, Halkin H Evaluation of appropriateness of blood and blood productstransfusion using present criteria Transfusion1989; 29: 473-476

19. Renner SW, Hawanitz JH, Fishkin BG Towards meaningful blood usage review compressive monitoring ofphysician practice Quall Rev Bull 1987; 13: 76-80

20. Blumberg N, Laczin J, McMican A, Heal J, Arvan D. A critical survey of fresh frozen plasma use Transfusion1986; 26: 511-513.

21. Yeh CJ, Wu CF, Hsu WT, Hsieh LL, Lin SF, Liu TC Transfusion audit of fresh 
frozen plasma in Southern Tiawan. Vox Sang 2006; 91: 270-274

22. Mollison PL. Blood transfusion in clinical medicine. Oxford, Blackwell Scientific, 2005.

23. McFarland W, Mvere D, Shandera W, Reingold A: Epidemiology and prevention of transfusion associated human immunodeficiency virus transmission in sub-Saharan Africa. Vox Sang 1997;72: 85-92.

24. Dzik WH, Emily Cooley Lecture 2002: transfusion safety in the hospital. Transfusion 2003; 43:1190-99. 